\title{
HISTOPATHOLOGIC FINDINGS IN A CASE OF SUPERIOR AND INFERIOR POLIENCEPHA. LITIS WITH REMARKS ON THE CEREBROSPINAL FLUID*
}

\author{
G. B. HASSIN, M.D.
}

Associate Professor of Neurology, University of Illinois College of Medicine; Histologist to the Illinois State Psychopathic Institute; Attending Neurologist Cook County Hospital CHICAGO

\section{REPORT OF CASE}

The patient, a man, 21 years of age, was admitted on Aug. 20, 1920, to the neurologic service of Cook County Hospital complaining of headache and vomiting, with inability to swallow and to judge distance.

Previous History.-There was nothing abnormal noticed in the history of the patient's childhood except poor vision and "inability to judge distance." At the age of 9 he went to school, but "could not learn fast" because of defective vision. He was infantile in his desires and preferred to play with babies and young children.

About six months before admission to the hospital he became dizzy and fell downstairs. He was picked up uninjured, but remembered nothing about the accident.

He began to complain of his present symptoms in the early part of July, 1920. The most distressing symptom was inability to swallow, which had been present for about six weeks. For two days after admission the patient was able to swallow only small amounts of liquids. During the same period of time speech became quite indistinct and almost unintelligible.

Headaches had been present for the last two years, mostly frontal in distribution. They had been coming in attacks which lasted for days or weeks and then spontaneously disappeared for two or three weeks. For the past six weeks vomiting without nausea would set in after each meal. During the six weeks prior to admission there was a marked increase in the strabismus which had been present, in a mild form, since birth.

Previous Illnesses.-Measles, whooping cough, mumps; he had had no operations and had received no injuries.

Family History.-The patient had five brothers and one sister living and well. One sister was not bright mentally; otherwise the family history was negative.

Examination.-The appearance of the patient was that of a not well-nourished boy, dull expression and defective mentality. He gave inadequate answers even to the simplest questions, though he was well oriented as to time and surroundings. There were no visible paralyses of the spinal nerves. but almost all the

\footnotetext{
* From the pathology laboratories of Cook County Hospital and Illinois State Psychopathic Institute.

* Read at a joint meeting of the Chicago Neurological and Ophthalmological Societies, Chicago, Dec. 16, 1920.
} 
cranial nerves were involved. Thus, the eyelids were drooping. especially the left; the eyeballs were almost totally inmovable, only slight movements up and down being possible. The palpeliral fissures were greatly narrowed. especially the left, which was represented by a narrow slit. The facial muscles were immobile, wrinkling of the forehead, widening of the mouth and puckering of the lips being almost impossible. The mastication muscles were markedly weak, the uvula and soft palate immobile, and swallowing even of small amounts of water was greatly impaired. In fact. the patient did not even attempt to swallow, as the food would "stick in the throat" and the liquids regurgitate through the nose. The tongue could not he protruded beyond the teeth; it showed twitchings and some atrophy but no deviation.

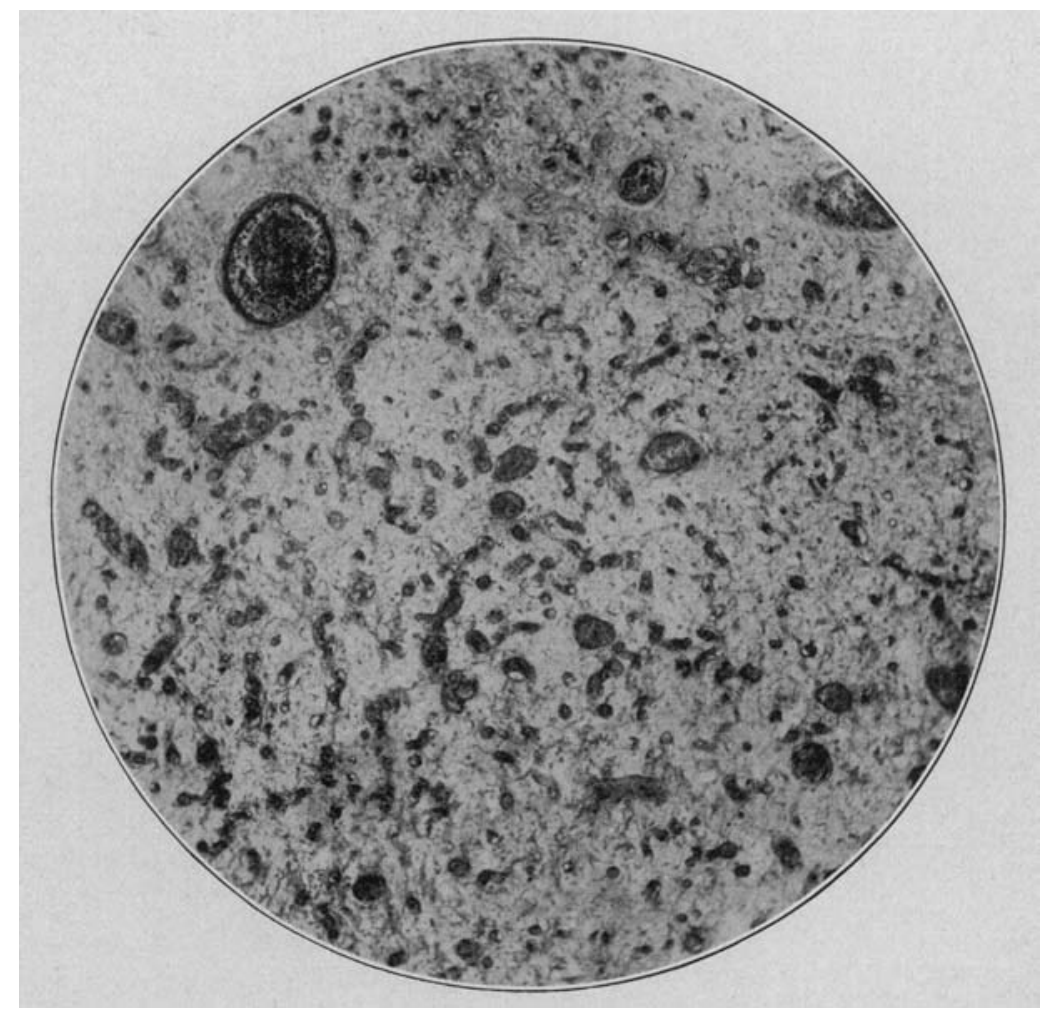

Fig. 1.-Tegmental portion of the pons. The entire area is covered by a great number of vessels and capillaries, represented in the illustration by dark. round bodies of various sizes. Some are so small that they can be seen only: with the help of a hand lens as minute capiliaries. The glia is vacuolated and covered by glia nuclei, ganglion cells and other structures photographed separately. Alzheimer-Mann stain: $\times 65$.

Refleres: Both pupils reacted to light; the corneal, conjunctival and pharyngeal reflexes were greatly diminished; the triceps, knee and ankle jerks were weak; the aldominal and plantar reflexes were normal; Babinski sign and ankle clonus were absent. Sensibility was normal. The muscle power in the extremities was fair: the deltoid, supraspinati and infraspinati and pectoral 
muscles were somewhat atrophied. The heart was slightly enlarged, the right limits reaching the right border of the sternum, the left limits reaching one inch beyond the left of the nipple line; the apex beat was palpable in the fifth intercostal space; there was a distinct systolic murmur. Examination of the chest revealed scattered râles on the right side. dulness over the apexes with bronchial breathing and a friction rub over the lower right lobe. Respiration was 40 , the pulse rate 84 and the temperature $99 \mathrm{~F}$. (by rectum).

The abdominal organs showed no abnormalities. The spinal fluid was under normal tension, colorless, with 5 lymphocytes per cubic millimeter and a negative Nonne test. More detailed examination of the patient's mental and physical condition was impossible as he died suddenly two days after admission.

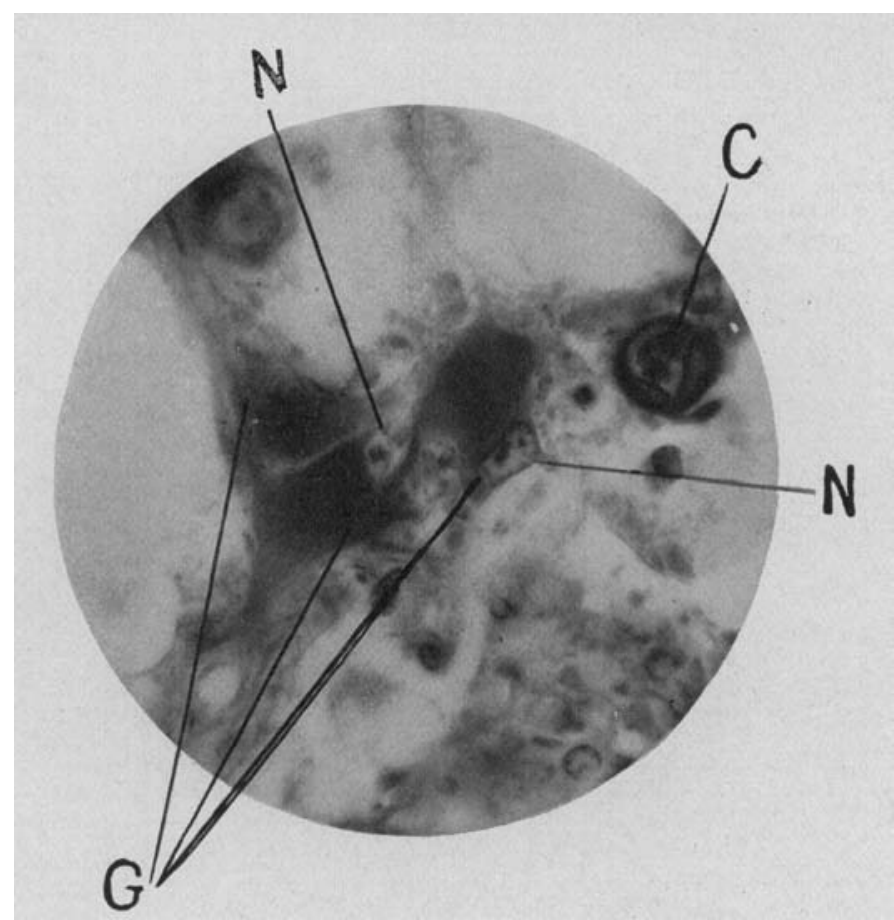

Fig. 2.-Three protoplasmic glia cells $(G)$ with the nuclei $(N, N)$ located at the very periphery. The processes of the homogeneous cell bodies are also quite distinct. At $C$ is a capillary with pronounced endothelial cells and a shoe-shaped polymorphonuclear leukocyte. Alzheimer-Mann stain; $\times 800$.

Summary of Findings.-The findings were: imbecility, loss of spatial sense, marked paralysis of the third, fourth, fifth, sixth, seventh, ninth and twelfth nerves, with partial involvement of the tenth and eleventh nerves on both sides.

The diagnosis was: imbecility, poliencephalitis superior and inferior.

Necropsy Findings.-(Permission was given to remove the brain only.)

The pia was smooth, easily detachable from the brain and shiny, except the portion over both occipitoparietal regions which showed marked hemorrhages. The convolutions were of normal size, not flattened and the sulci of usual depth. The gray matter of the midbrain and medulla appeared unusually dark, almost black, sharply contrasting with the surrounding white substance. Foci of hem- 
orrhages or softening were absent; the ventricles were not enlarged and the ependyma not proliferated.

Microscopic Examination.-Various portions of the cortex, midbrain, medulla and cerebellum, including the pia-arachnoid and both third nerves. were studied in celloidin, paraffin and frozen sections. The staining methods used were toluidin blue, thionin. Alzheimer-Mann, Bielschowsky, Herxheimer and combined Alzheimer-Mann-Bielschowsky. As the main pathologic changes were expected in the midbrain and medulla, these regions will be described in somewhat greater detail.

Photomicrograph 1, showing the condition of the tegmental portion of the pons, gives a fair idea of the principal changes encountered in the midbrain

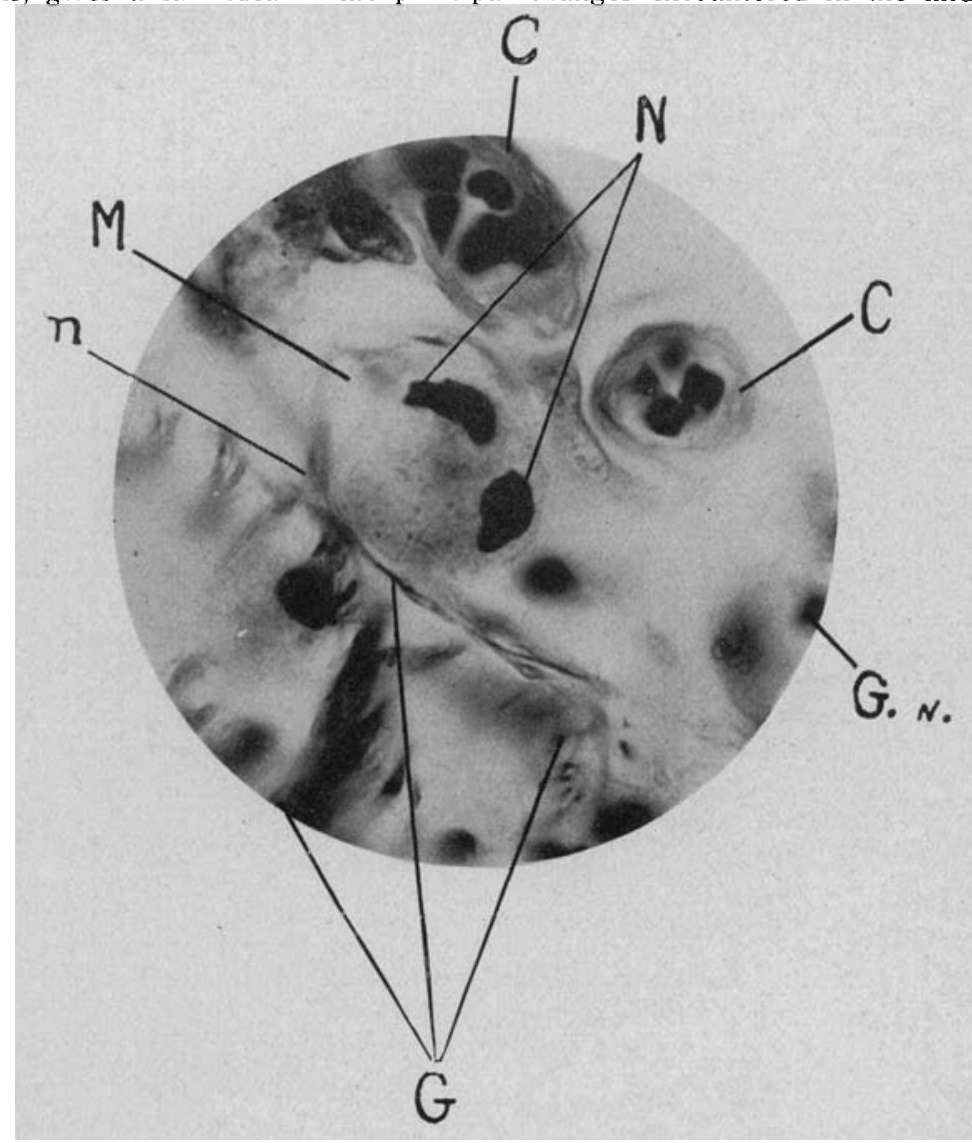

Fig. 3.-Tegmental region of the pons. $M$ is a myelophage with a nucleus (n) and two fragments of an axon (N). C,C are capillaries containing four and five blood cells. The thick and other dark stained strips $(G)$ are glia fibers; $G$. $n$. are glia nuclei. Bielschowsky stain; $\times 1200$.

and medulla. The visual field consisted of vacuolated glia tissue with wide meshes and a great amount of hyperemic and distended vessels. The smallest capillaries were unusually prominent and engorged with blood (Figs. 2 and 3). Often there could be found newly formed capillaries in the form of elongated 
adventitial and hypertrophied, brightly stained endothelial cells. Such young vessels usually were free from blood elements. The adventitial spaces of larger as well as of smaller vessels, did not show infiltration cells, such as lymphocytes, plasma cells or polyblasts. Neither could polymorphonuclear cells be found, while in some instances erythrocytes could be seen scattered freely or enclosed within various gliogenous formations. In the large ganglions, especially the lenticular nucleus, the vascular walls sometimes appeared thickened and some-

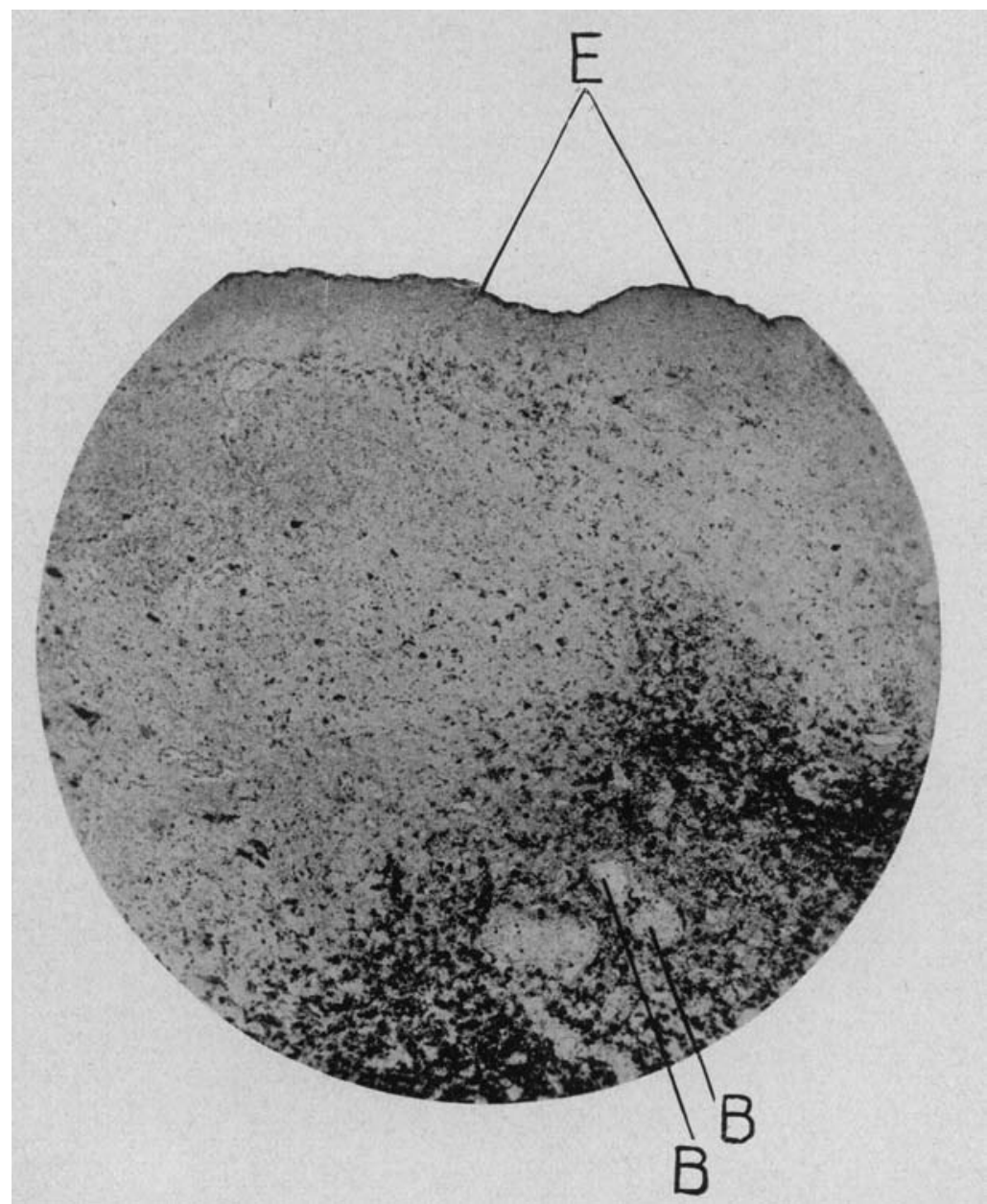

Fig. 4.-The region of the twelfth nucleus. The black masses are fat globules covering the area occupied by the twelfth nucleus and scattered as small droplets over the subependymal region. $B B$ are blood vessels surrounded by fat enclosed within gitter cells; other pale areas in the darkened area are mostly vessels; at $E$ is the ependyma of the fourth ventricle. Herxheimer scarlet-red-hematoxylin stain; $\times 60$.

times showed proliferation of adventitial and endothelial elements with an abunclance of brownish-green, round granules. Similar vascular changes also 
could be found in the cortical layers, especially in the occipital lobe, to a lesser extent in the cerebellum, and were quite pronounced in the choroid plexus.

The characteristic feature of the vascular changes was the almost universal presence of fat within or around the vessel walls, including those of the smallest capillaries. The latter, stained with scarlet red, showed enormous quanti-

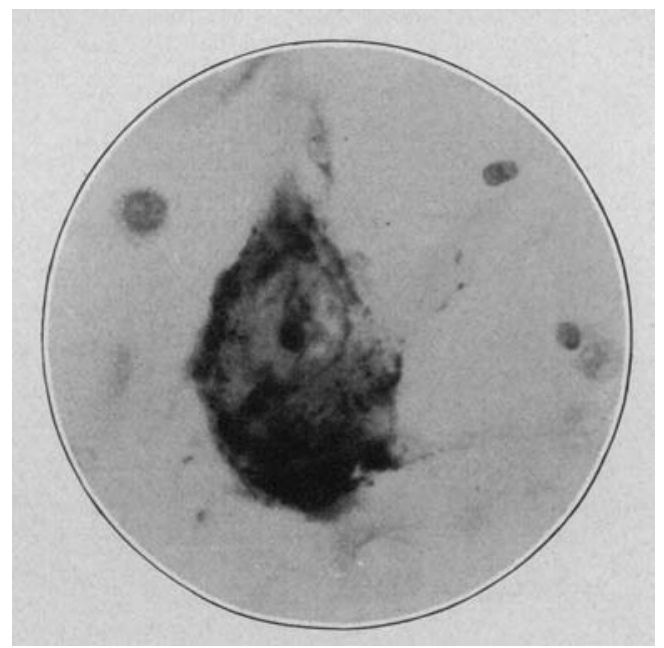

Fig. 5.-One of the types of ganglion cell changes; central chromatolysis and other changes. Toluidin-blue stain.

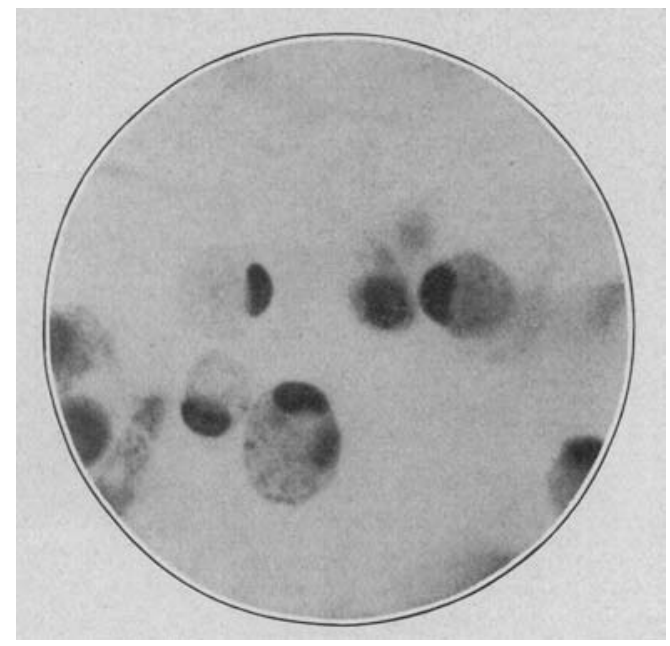

Fig. 6.-Gitter cells $(\gamma)$ of one of the degenerated areas. One cell contains two nuclei. Toluidin blue stain; $\times 1200$.

ties of fat which covered the entire visual field (Fig. 4), and made it impossible to discern any other structures except vessels and their contents.

Ganglion Cell Changes.-The ganglions sometimes appeared quite normal, even in those regions of the midbrain which exhibited marked structural 
changes in the glia and lhood vessels. Many nerve cells were decidedly pathologic, appearing atrophied, excarated and surrounded or invaded by a great number of glia cells. Other cells were sclerosed or homogeneous with deeply stained dendrites. dustlike chromatin and a dislocated nucleus poor in chromatin but possessing a well preserved membrane (Fig. 5). In short, chromatolysis, satellitosis and neuronophagia were the usual changes found in the ganglion cells. Stained with scarlet red. they always showed an abundance of fat drops and droplets over the entire cell body, including the nucleus.

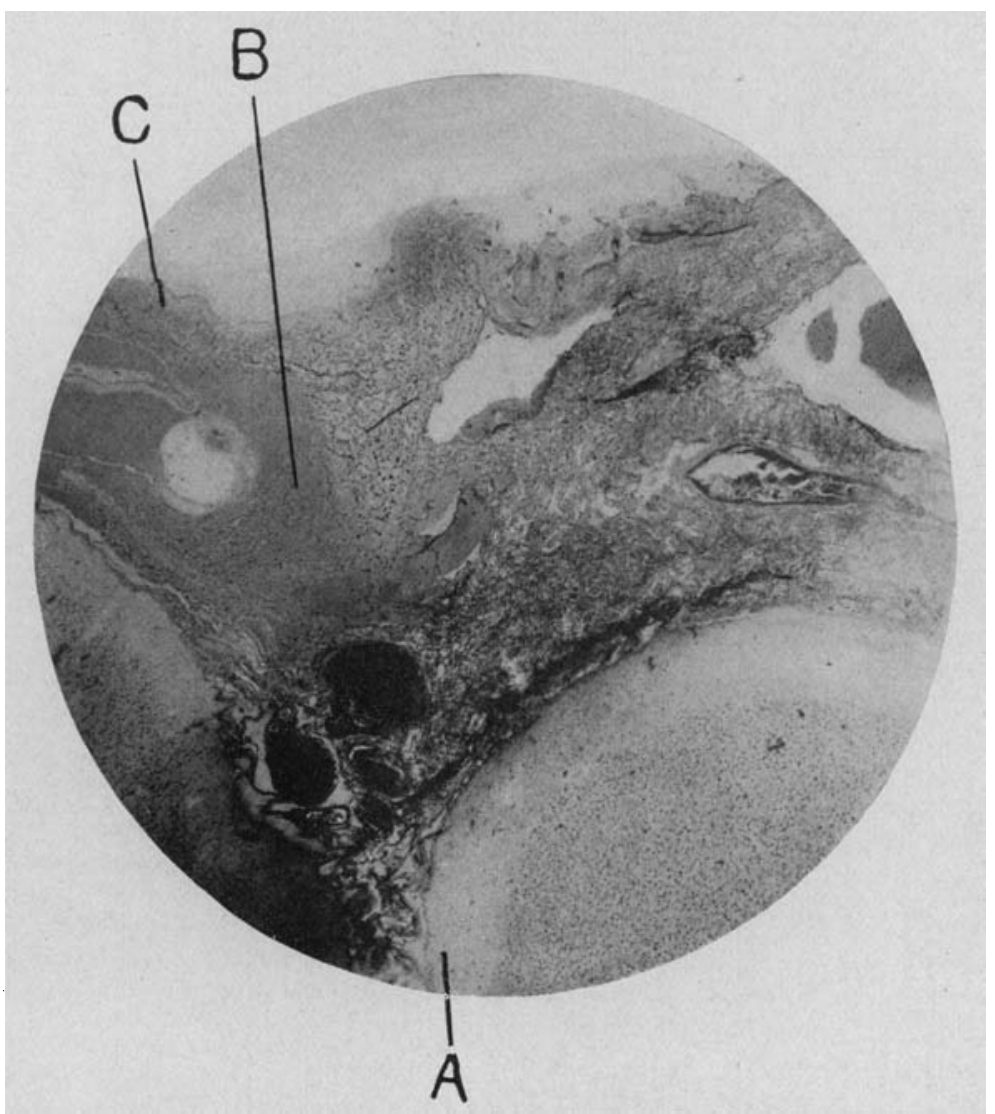

Fig. 7.-Cortex of the angular gyrus covered by a pia-arachnoid which is infiltrated with various cells and shows an abundance of blood vessels. The subpial layer $A$ appears hyperplastic; $B$, hemorrhagic focus; $C$, arachnoid membrane. Toluidin-blue stain; $\times 16$.

The foregoing cellular changes, the fat-laden ganglion cells, together with the vast accumulation of fat around the extremely numerous vessels, were especially marked around the third and fourth ventricles and the Sylvian aqueduct; that is to say, they involved the nuclei of all cranial nerves, from the third to the twelfth. including the locus coeruleus. while the gray matter of the substantia nigra, nucleus ruber and basal portion of the pons were either entirely normal or showed but mild changes. 
Glia Tissue Changes.-Marked as the changes in the gray matter were, those of the neuroglia were much more striking. The wide meshes of glia, appearing under the low power as empty vacuoles, exhibited, under the high power, especially with oil immersion, a great variety of unusual structures: (1) large

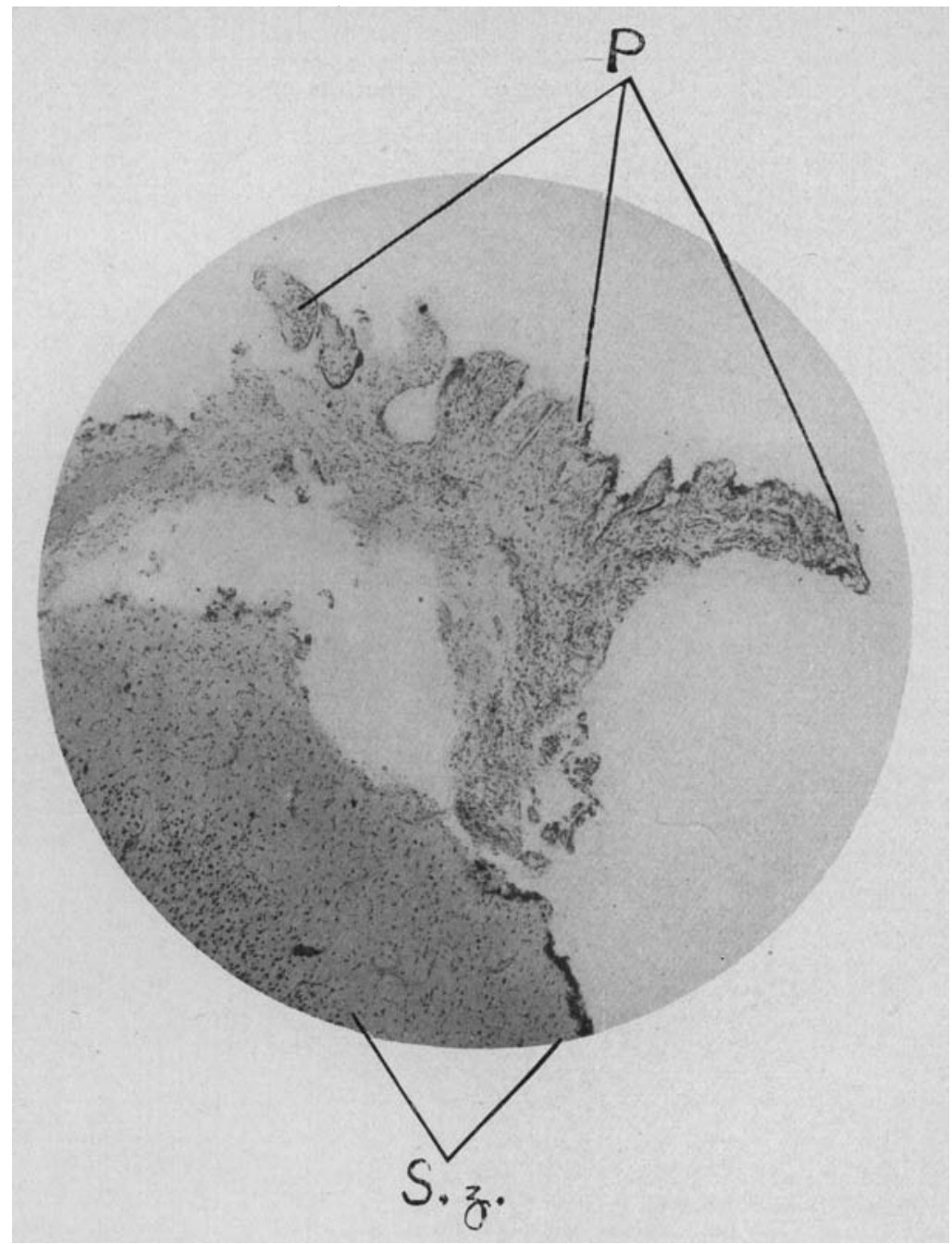

Fig. 8.-Pia-arachnoid of the motor area. The arachnoid is greatly infiltrated, mostly with gitter cells and mesothelial cells reproduced on photomicrograph 9. The arachnoid villi (pacchionian bodies) are well shown. $P$ represents the pacchionian hodies (arachnoid villi) ; $S$. z., the stratum zonale (subpial layer) is hyperplastic and covered by an abundance of glia nuclei. Toluidinblue stain; $\times 36$.

round lattice-like reticular bodies, commonly described as "gitter" cells; (2) fragments of myelin and axons; (3) red blood corpuscles; and (4) various gliogenous formations (protoplasmic glia cells, myelophages). 
The gitter cells were the most numerous elements, mostly in the form of round bodies wholly made up of fine vacuoles and without processes; their nucleus was flattened and misplaced to the periphery (Fig. 5). Some cells contained more than one nucleus and were abundant around capillaries and smaller vessels. Equally numerous were gitter cells that, in addition to the great mass of small vacuoles, exhibited one large vacuole containing remnants of broken-up nerve tissue. These are so-called gitter cells-a according to Jacob's classification.

Scarlet red stained specimens frequently exhibited a third variety of gitter cells, irregular in shape and possessing a great many processes packed with fat (gitter cells- $\beta$ ).

Aside from these three varieties of gitter cells, there were numerous other round formations with several large vacuoles, of which some were filled with

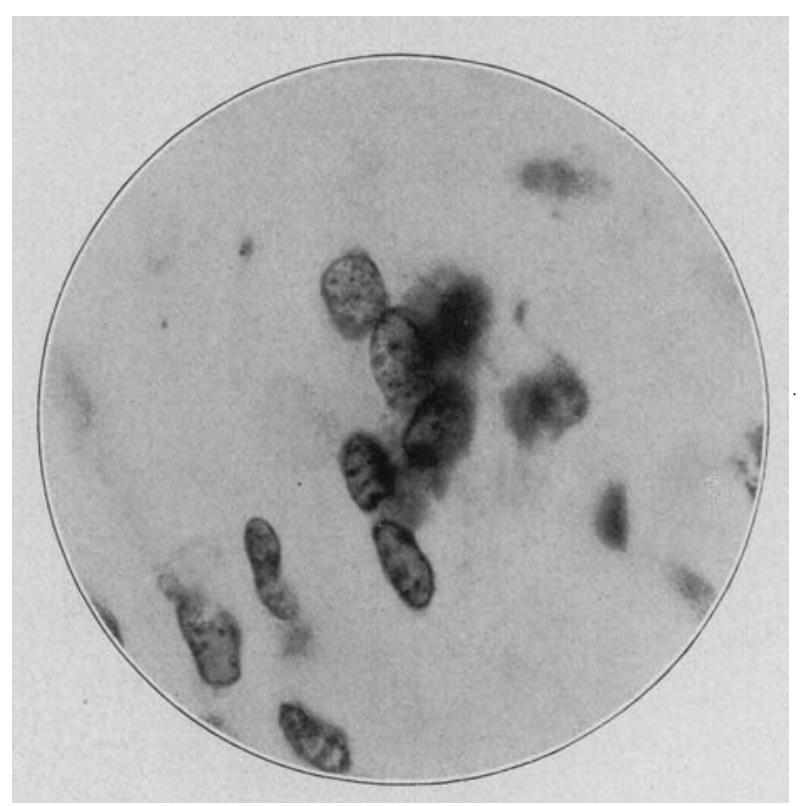

Fig. 9.-Clusters of mesothelial cells of the subarachnoid space. Toluidin. blue stain; $\times 1200$.

red blood cells and remnants of axons and myelin, well shown in photomicrograph 3. These are myelophages (Jacob) which, like the foregoing types of gitter cells, are gliogenous formations with a specific function. For instance, the function of the myelophages is to pick up the broken-up myelin or axon and transform it into fat which is stored up in the gitter cells. It is probable that the myelophages themselves become transformed into gitter cells after their contents, myelin and axon, have been, so to speak, digested and transformed into fat. The $\gamma$-variety represents the ripe stage of gitter cells and is to be found freely scattered or around the vessels to which they are supposed to deliver the fat for final elimination.

In the large ganglions (lenticular nucleus, optic thalamus, caudate nucleus) the basal portion of the pons, cerebral and cerebellar cortices, as well as in the 
subarachnoid space only the $\gamma$-variety could be encountered, the other types including myelophages, being absent.

There were in the midbrain and medulla a great number of other atypical glia cells, so-called protoplasmic glia cells. Figure 2 shows such formations, rich in protoplasm, homogeneous in appearance and well supplied with processes. The chromatin-rich nucleus was misplaced toward the periphery of the cell body as if about to desert it. The processes, in many cells, were very large and stretched for a long distance, breaking up into numerous glia fibers. Often they enveloped red cells or remnants of broken-up brain tissue, such as ganglion cells, myelin globules and even smaller capillaries. The size of the proto-



Fig. 10.-Fat globules (black dots) in the subarachnoid space. Herxheimer scarlet-red stain ; $\times 230$.

plasmic glia cells may be quite large, somewhat resembling the monster or giant glia cells of a spinal cord involved in secondary degeneration.

Finally, many glia cells were represented by mere nuclei which, however, were always increased in size and rich in chromatin. This type of glia cells predominated in the larger ganglions and basal portion of the pons and cortex. Stained with scarlet red they showed minute globules of fat.

Nerve Fibers.-These were frequently pale, poorly stainable, sometimes swollen or tumefied, and therefore irregular in shape. Frequently they were broken up into smaller fragments enveloped by glia fibers; or they formed globules of myelin (Marchi globules) enclosed within the previously described 
gliogenous formations. Frequently a changed nerve fiber was accompanied by, or made up of, strips of thin, delicate, densely red fibrils (degenerated axons).

The cortical layers, which were studied from every portion of the brain and cerebellum, showed changes analogous to those of the large ganglions, namely, excessive vascularization, numerous protoplasmic glia cells filled with fat droplets and various ganglion cell changes (neuronophagia, cell sclerosis and chromatolysis). Equally well represented all over the cortex, they were especially marked in the occipital lobe, the region of cuneus and precuneus and especially the angular gyrus.

The latter was studied with particular care, in view of the history of disturbances of the spatial sense which is supposed to be located in this portion of the cortex. Photomicrograph 7 shows this part of the cortex covered with

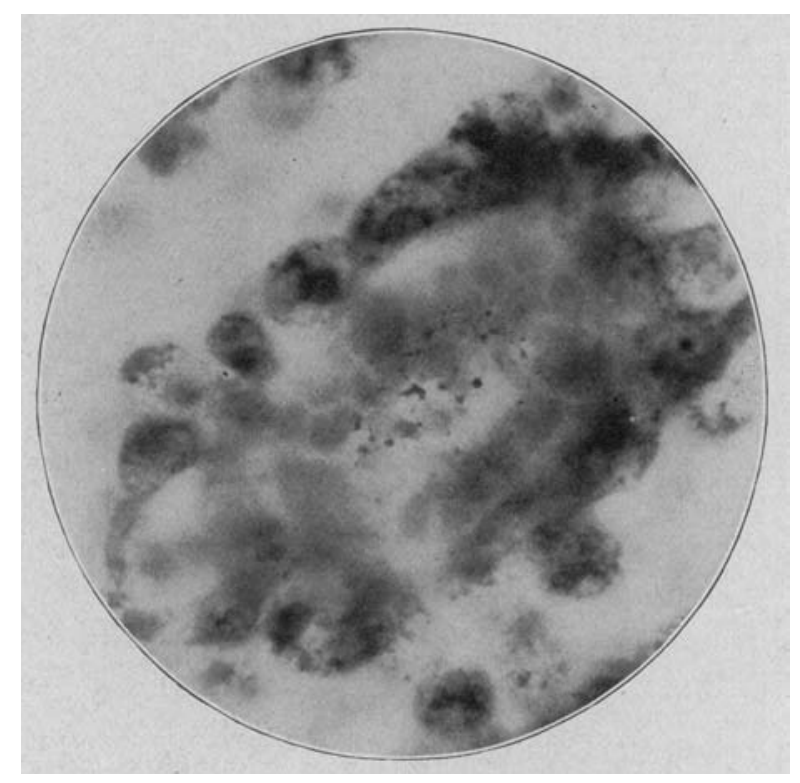

Fig. 11.-Choroid plexus. An engorged vessel surrounded by enlarged cystic epithelial cells showing granules within the cytoplasm. Toluidin-blue stain; $\times 800$.

an enormously distended and hemorrhagic pia-arachnoid which also exhibits unusually interesting findings over the rest of the cortex, especially on the base of the brain.

The distended meshes of the pia-arachnoid were packed with a great amount of various types of cells (Figs. 7 and 8 ). The latter were principally mesothelial (Fig. 9) and gitter cells mixed with an abundance of red cells. There were also in evidence numerous minute granules covering the meshes, the mesothelial (around their nuclei) and partly the gitter cells. Surface frozen sections of the pia arachnoid exhibited great masses of fat (Fig. 10) enclosed within gitter cells and gathered around the capillaries. The latter were numerous, distended, showed well stained adventitial and endothelial cells but no infiltration elements, such as lymphocytes, plasma cells, etc. 


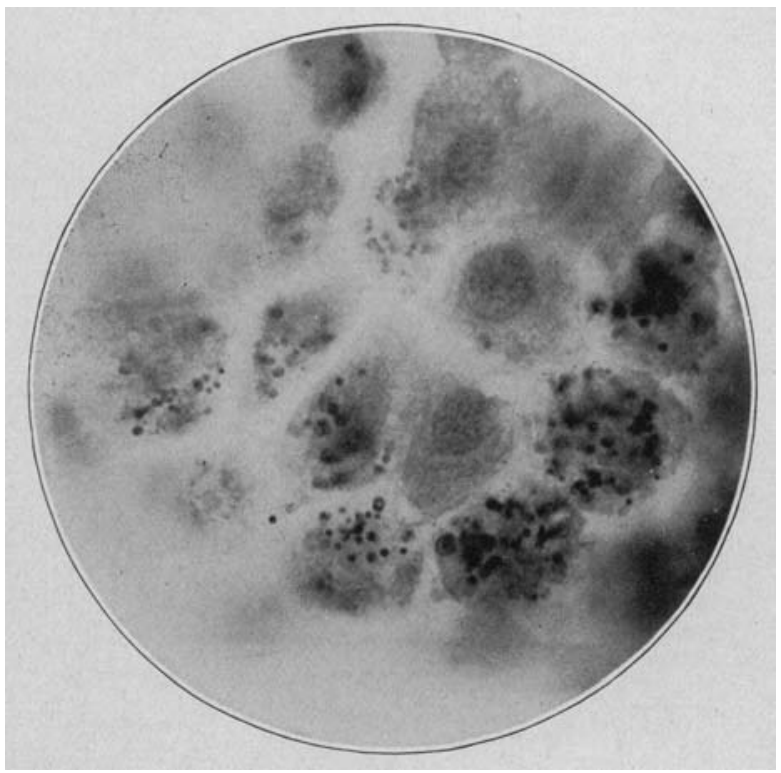

Fig. 12.-The epithelial cells of the choroid plexus packed with fat granules. Herxheimer scarlet-red; $\times 1200$.



Fig. 13.-Same as photomicrograph 12. Some of the cells assumed the shape and form of gitter cells. Herxheimer scarlet-red stain; $\times 1200$. 
In some toluidin blue specimens could be seen cell bodies with pale chromatin-poor nuclei surrounded by a rim of metachromatically stained cytoplasm. They were mostly irregular in shape and numerous in the arachnoid portion of the pia. Such ill-defined elements most probally were changed mesothelial cells which, like the typical cells, could be seen all over the subarachnoid space, regardless of the localization. They were quite numerous on the base, while over the angular gyrus they were olsscured by extensive hemorrhages.

Noteworthy changes were also found in the choroid plexus. The ressels were engorged. the endothelial and adventitial cells of the capillaries promi-

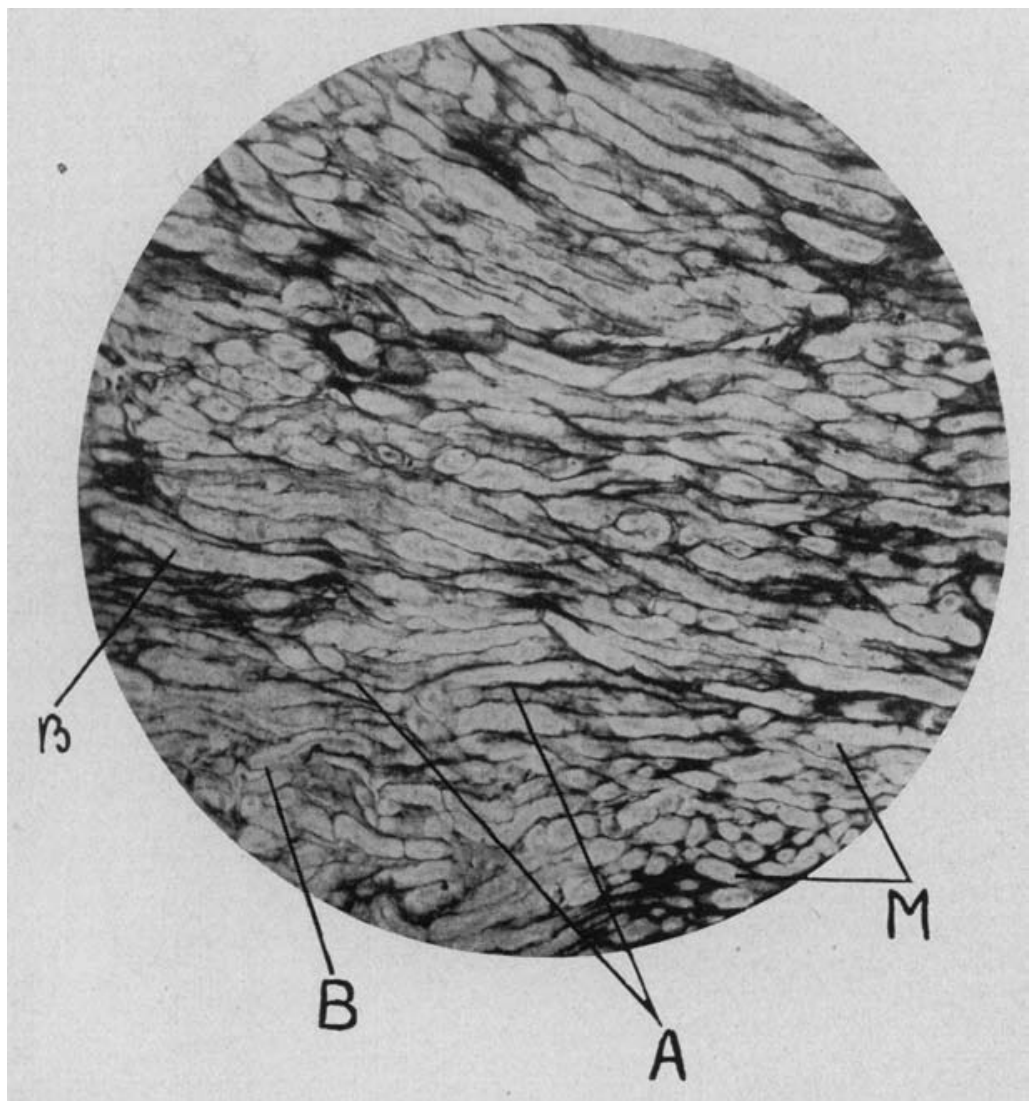

Fig. 14.-The third nerve broken up into numerous fragments; the axons can be well seen in the majority of the nerve fibers. The right lower area is filled with Marchi globules. $A$ represents the Schwann membrane; $B B$, axons; M. Marchi globules. Alzheimer-Mann-Bielschowsky stain; $\times 150$.

nent and the epithelial cells surrounding the vessels appeared as unusually large, expanded, reticular bodies which were well stainable and contained a peripheral nucleus (Fig. 11). Unstained specimens exhibited the usual black granules. while those stained with scarlet red showed a great number of fat droplets scattered over the cytoplasm (Figs. 12 and 13). 
The third nerve, in its distal portion, was converted into numerous so-called Marchi-globules (Fig. 14), that is to say, fragments of myelin and axons, enveloped by proliferated glia tissue (Schwann cells). These changes are well represented in Figure 14 and are characteristic of secondary nerve degeneration in its early stages.

The spinal cord changes could be studied only in the upper cervical portion, which showed mild vascular and parenchymatous changes. These were even less pronounced than those of the cortex or basal ganglions.

Summary of Findings.-The findings were: widespread degenerative changes of every portion of the cerebrum and cerebellum with particular involvement of the midbrain and medulla; marked secondary proliferative changes in the glia tissue and, to a lesser extent, in the vessels; fatty infiltration of the vessels of the brain, pia-arachnoid and choroid plexus.

\section{DISCUSSION}

Quite throughout, the changes were particularly striking in the midbrain and medulla, where they exhibited a typical picture of various stages of so-called secondary degeneration, as described by A. Jacob in experimental animals. Jacob's ${ }^{1}$ findings, discussed by $\mathrm{me}^{2}$ at some length elsewhere, resemble the conditions to be found in amyotropinic lateral sclerosis, subacute combined cord degeneration, progressive bulbar paralysis and, to a large extent, in tabes and multiple sclerosis. The case under discussion differs from the foregoing by the principal, though not exclusive, involvement of the midbrain and medulla oblongata. In this respect it is almost analogous to another mesencephalic lesion-lethargic or epidemic encephalitis. The latter, however, is a purely inflammatory process, due to some infection, while the case under discussion is not inflammatory or infectious. It is most probably caused by some organic toxin, as is evidently the case in amyotrophic lateral sclerosis, subacute combined cord degeneration and similar conditions.

The term poliencephalitis superior hemorrhagica applied to certain cases, including the present one, is therefore a misnomer, as already pointed out by Schroeder, ${ }^{3}$ among others. First of all, hemorrhages are not essential. They may be entirely absent (Oppenheim and Cassirer ${ }^{4}$ ), or, as in this case, be so small that only careful microscopic search reveals them. It is therefore altogether illogical to look on these microscopic hemorrhages as the cause of the widespread degenerative changes

1. Jacob, A.: Ueber die feinere Histologie der secundären Faserdegeneration in der weissen Substanz des Rückenmarks, Nissl-Alzheimer's Arb. 5:1, 1912.

2. Hassin, G. B.: Histopathological Changes in a Case of Amyotrophic Lateral Sclerosis, Med. Rec. 91:228 (Feb. 10) 1917.

3. Schroeder, Paul: Zur Lehre von der akuten hämorrhagischen Poliencephalitis superior (Wernicke), Nissl-Alsheimer's Arb. 2:145, 1908.

4. Oppenheim, H., and Cassirer, R.: Die Encephalitis, in Nothnagel's Specielle Pathologie und Therapie, Wien. 9: Pt. 2, 39, 1909. 
and the marked progressive glia phenomena, an opinion expressed by Schroeder. The cause as stated is probably some organic toxin or catabolic phenomena which seems to possess the peculiar ability to affect certain portions of the central nervous system leaving others intact. For instance, the pure motor elements may alone be affected and give rise to the clinical syndromes of amyotrophic lateral sclerosis, buibar paralysis or progressive muscular atrophy; or the white substance, principally of the spinal cord, may be exclusively involved, leaving the motor and sensory elements undamaged and thus produce a condition of subacute combined cord degeneration. The action of the problematical (catabolic) toxins is thus selective causing a great variety of morbid conditions which, though pathologically similar, are dissimilar in localization.

The histologic studies of this case bring forth some other interesting facts. The presence of fat granule bodies (gitter cells) in the subarachnoid space and the choroid plexus, as well as in the perivascular spaces, all over the brain stem and the cerebellum can be explained only by assuming that they reached these structures, or had been transported to them, from the degenerated areas of the midbrain. In other words, the great masses of fat were gradually drained from the midbrain regions by way of perivascular spaces toward the subarachnoid space.

The latter thus may be looked on as the receptacle of the waste products discharged by the brain tissues. Sone of these waste products are lipoid substances, some probably are represented by the numerous granules in the subarachnoid space. The proliferation of the mesothelial cells and the abundance of other, mostly ill-defined, elements is probably a reaction against the invading waste products, just as they react against invasion by some particular matter (Essick," Weed ${ }^{6}$ ).

Whei these products reach the subarachnoid space they are removed thence by the cerebrospinal fluid. If the latter is to be considered as the product of the choroid plexus, then the function of the cerebrospinal fluid is to wash off the waste products that come from the brain to the subarachnoid space.

The choroid plexus, however, exhibited an abundance of fat in the epithelial cells and its vessels. The fat could come only from the spinal fluid which thus gets rid, with the help of the choroirl plexus, of some of its contents-in this case of the lipoids.

One gains an impression that the spinal fluid is entirely made up of the tissue fluids of the brain and is being continually discharged by way

5. Essick, C.: Formation of Macrophages loy the Cells Lining the Subarachnoid Cavity in Response to the Stimulus of Particulate Matter, Pulblication 272 of the Carnegie Institution in Washington, pp. 377 and 388.

6. Weed, L. H.: The Cells of the Arachnoid, Bull. Johns Hopkins Hosp. 31:343 (Oct.) 1920. 
of the perivascular spaces of the cerebral vessels into the subarachnoid space. Weed ${ }^{\tau}$ admits such a possibility though he believes that only smail amounts of cerebrospinal fluid originate in this manner. Yet, coming as it cloes from such a voluminous and active organ as the brain, the cerebral fluid necessarily must be abundant and rich in proteins and various waste products. Before being absorbed by the arachnoid villi and other channels, the fluid becomes cleared, as it were, by the choroid plexus and thus rendered more passable.

Further pathologic studies of cases like the one recorded will, to a great extent, facilitate the solving of these highly difficult and interesting problems. The facts brought forth by histopathologic studies of the subarachnoid space and the choroid plexus may show that the function of the cerebrospinal fluid and the choroid plexus is altogether different from the one generally accepted.

\section{CONCLUSION}

1. Poliencephalitis superior (hemorrhagica) of Wernicke is not an inflammatory, but a partial manifestation of a general degenerative process of the central nervous system.

2 . It is analogous to other degenerative processes, such as amyotrophic lateral sclerosis, subacute combined cord degeneration, progressive bulbar paralysis and tabes dorsalis, from which it differs by the localization of the degenerative phenomena.

3. It is essentially, though not exclusively, a mesencephalic lesion, resembling in its localization epidemic encephalitis which, however, is not a degenerative but an inflammatory process.

4. The subarachnoid space is a receptacle of the tissue fluids which carry away the waste proclucts of the brain.

5. The function of the choroid plexus is probably to pick up from the cerebrospinal fluid harmful or other products and to render them, as well as the fluid, more absorbable.

7. Weed, L. H.: Studies on Cerebrospinal Fluid, Article IV: The Dual Source of Cerebrospinal Fluid, Jour. Med. Research 31:93, 1914. 